STOMACH

\title{
Pericryptal fibroblast sheath in intestinal metaplasia and gastric carcinoma
}

\author{
H Mutoh, S Sakurai, K Satoh, H Osawa, T Tomiyama, H Kita, T Yoshida, K Tamada, H Yamamoto, \\ N Isoda, K Ido, K Sugano
}

See end of article for authors' affiliations

.....................

Correspondence to: Dr H Mutoh, Department of Gastroenterology, Jichi Medical School, Yakushiii 3311-1, Minamikawachimachi, Kawachigun, Tochigi 329-0498, Japan; muto@jichi.ac.jp

Revised version received 27 May 2004

Accepted for publication 3 June 2004
Background and aims: In the progression of chronic gastritis, gastric mucosal cells deviate from the normal pathway of gastric differentiation to an intestinal phenotype which is closely related to gastric carcinoma. However, to date, it has not been elucidated whether the intestinal metaplasia is merely a change in the epithelium or whether the underlying mesenchyme also changes from gastric type to intestinal type. We have investigated the relationship between intestinal metaplasia and the pericryptal fibroblast sheath (PCFS) in the mesenchyme. In addition, we also examined PCFS in gastric carcinoma. Methods: We determined the existence of PCFS in the intestinal metaplastic mucosa and carcinoma of both human and $\mathrm{Cdx} 2$ transgenic mouse stomach. PCFS was determined using the antibody against $\alpha$-smooth muscle actin and electron microscopic observations.

Results: PCFS formed an almost complete layer around the small and large intestinal crypts while it did not exist around the normal gastric glands in both mice and humans. PCFS was seen around the glands of intestinal metaplastic mucosa in both $\mathrm{Cdx} 2$ transgenic mouse and human stomachs. However, PCFS was virtually absent in the intestinal-type gastric adenocarcinoma area.

Conclusion: We successfully demonstrated that the epithelium as well as the mesenchyme changed from the gastric type to the intestinal type in intestinal metaplasia and that PCFS disappeared in intestinal-type gastric carcinoma.
$\mathrm{H}$ uman intestinal-type gastric carcinoma is associated with gastric atrophy and intestinal metaplasia that are caused mainly by Helicobacter pylori infection. Correa presented a hypothesis with respect to the mechanism of gastric carcinogenesis due to $H$ pylori infection. ${ }^{1} H$ pylori infection is involved in the process of progression from normal gastric mucosa to superficial gastritis, chronic active gastritis, atrophic gastritis, and finally to intestinal metaplasia. ${ }^{1}$ The terminal stage of this process is gastric carcinoma.

We and others have reported that the intestinal specific transcription factor $\mathrm{Cdx} 2$ is expressed in human gastric intestinal metaplastic mucosa. ${ }^{2-6}$ Furthermore, we established $\mathrm{Cdx} 2$ transgenic mice expressing the transcription factor $\mathrm{Cdx} 2$ exclusively in the gastric epithelium. ${ }^{7}$ The gastric fundic mucosa of the $\mathrm{Cdx} 2$ transgenic mouse was completely changed into intestinal metaplastic mucosa. However, whether intestinal metaplasia is limited to the epithelium or influences the underlying mesenchyme has not been elucidated as it is difficult to discriminate intestinal mesenchyme from gastric mesenchyme.

The normal intestinal crypt of Lieberkühn is invested by a mesenchymal sheath, a specialised part of the lamina propria consisting of fibroblasts tightly surrounding the epithelium and of collagen fibres oriented circumferentially to the crypt. ${ }^{8}$ The mesenchymal sheath is a distinct and highly organised system of fibroblasts immediately subjacent to the epithelial basement membrane located at the epithelial-mesenchymal interface. The highly specialised fibroblasts, that were reported as pericryptal fibroblasts by Kay and colleagues, ${ }^{9}$ form the pericryptal fibroblast sheath (PCFS). PCFS consists of a network of fibroblast cells and extracellular matrix immediately subjacent to the crypt epithelial cells. ${ }^{8}{ }^{10}$ Such pericryptal fibroblasts under the basement membrane envelop the glands of the intestine, are seen as elongated cells tightly appliquéd to the base of the epithelial cells of the crypt, have a fusiform appearance, and follow the contours of the wall of the crypt. Fibroblasts of the PCFS have an important role in colonic fluid absorption. ${ }^{11}$ Colonic absorptive function depends not only on crypt luminal cells but also on the fibroblast cells of the surrounding pericryptal sheath. ${ }^{11}$

There is a close interactive epithelial-mesenchymal relationship between the epithelial cell system and the underlying pericryptal fibroblast system to maintain the normal structure and function of the crypts of Lieberkühn. ${ }^{89}$ Pericryptal fibroblasts have been shown to play a fundamental role in epithelial differentiation via epithelialmesenchymal cell interactions during both fetal and adult life. ${ }^{12}{ }^{13}$ The PCFS is a self renewing population of mesenchymal cells in close contact with the intestinal epithelium; its cells maintain a parallel relationship in replication, migration, and differentiation with the overlying epithelium suggesting that it is involved in the maintenance of the normal structure and function of the intestinal mucosa. ${ }^{89}$ Autoradiographic studies in rabbit colon after ${ }^{3} \mathrm{H}$-thymidine injection demonstrate steady state renewal of pericryptal fibroblasts and migration to upper portions of the synchrony with epithelial migration. The fibroblast progenitor population, like that of the epithelium, is in the deep one third of the crypt. ${ }^{8}$ The kinetics of this portion of the normal intestinal mucosa suggest that the pericryptal fibroblasts and the epithelium act as a unit to maintain the normal structure, maturation, and function of the crypt of Lieberkühn. ${ }^{8}$

These findings prompted us to investigate (1) whether intestinal metaplasia influences the epithelium as well as the formation of the PCFS and (2) the relationship between PCFS and intestinal-type gastric carcinoma.

Abbreviations: PCFS, pericryptal fibroblast sheath; $\alpha$-SMA, $\alpha$-smooth muscle actin; PBS, phosphate buffered saline 

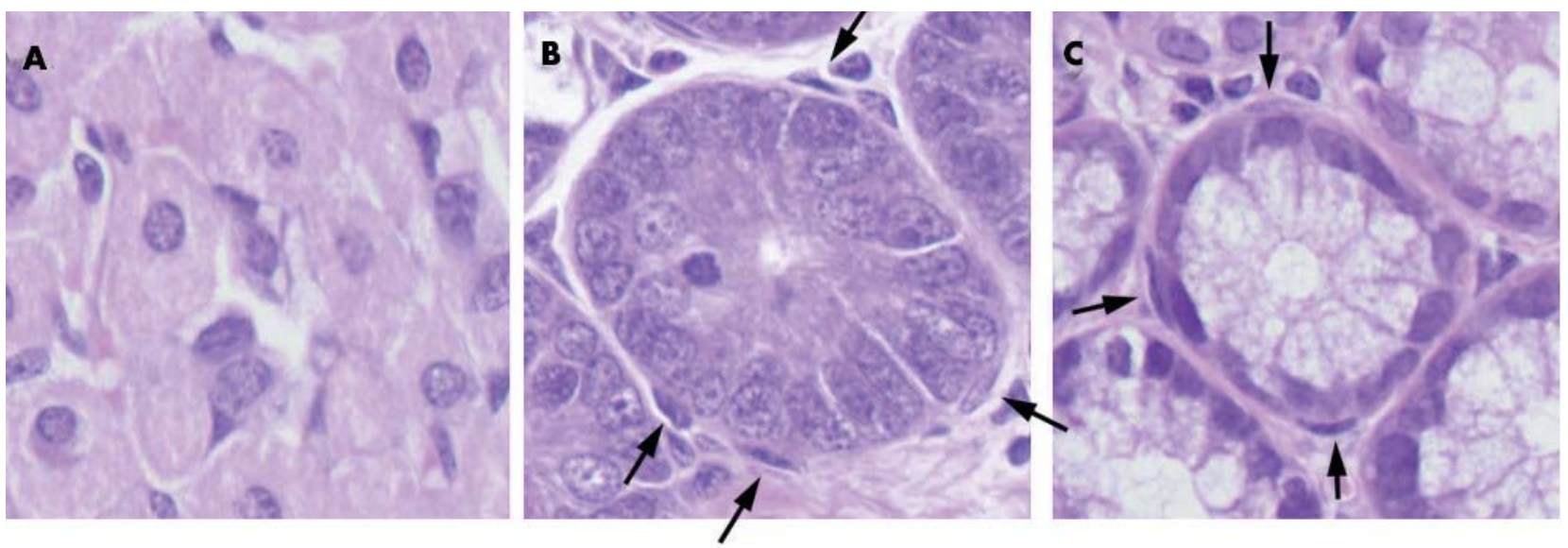

Figure 1 Mouse gastric glands (A), small intestinal crypts (B), and large intestinal crypts $(C)$ shown in cross section. Cross sections of crypts of mouse small (B) and large (C) intestines show pericryptal fibroblast nuclei (arrows) immediately subjacent to the epithelial cells. The long axis of each pericryptal fibroblast is perpendicular to that of the crypt. Pericryptal fibroblast nuclei are not seen forming a sheath round the glands of mouse gastric mucosa (A). Magnification $\times 400$.

\section{MATERIALS AND METHODS \\ Cdx2 transgenic mice}

We used Cdx2 transgenic mice with stomach specific expression of $\mathrm{Cdx} 2$ using the $\beta$-subunit gene promoter of rat $\mathrm{H}^{+} / \mathrm{K}^{+}$-ATPase. ${ }^{7}$ The gastric mucosa of $\mathrm{Cdx} 2$ transgenic mice was completely changed to intestinal metaplastic mucosa. $^{7}$

\section{Histology}

Stomach tissue specimens were fixed in neutral buffered $10 \%$ formalin for 12-24 hours, washed in 70\% ethanol, processed by standard methods, embedded in paraffin, sectioned at $3 \mu \mathrm{m}$, and stained with haematoxylin and eosin for histological evaluation.

\section{Immunohistochemistry}

Thick sections $(3 \mu \mathrm{m})$ were cut, deparaffinised, rehydrated in phosphate buffered saline (PBS), placed in $10 \mathrm{mM}$ citrate buffer ( $\mathrm{pH} 6.0$ ), and heated in an $850 \mathrm{~W}$ microwave for 15 minutes to recover antigenicity. Endogenous peroxidase activity was blocked by incubation for 30 minutes in methanol containing $0.3 \% \mathrm{H}_{2} \mathrm{O}_{2}$. After washing twice with PBS, including $0.1 \%$ Triton $X-100$, sections were preincubated with blocking buffer (Dako, Carpinteria, California, USA) for 15 minutes at room temperature. Primary antisera, anti- $\alpha$ smooth muscle actin ( $\alpha$-SMA) (1:100; Dako), or anti-Cdx2 (1:100; BioGenex, San Ramon, California, USA) were diluted in PBS and incubated overnight at $4^{\circ} \mathrm{C}$. Slides were then washed in PBS and incubated with Envision (Dako). After
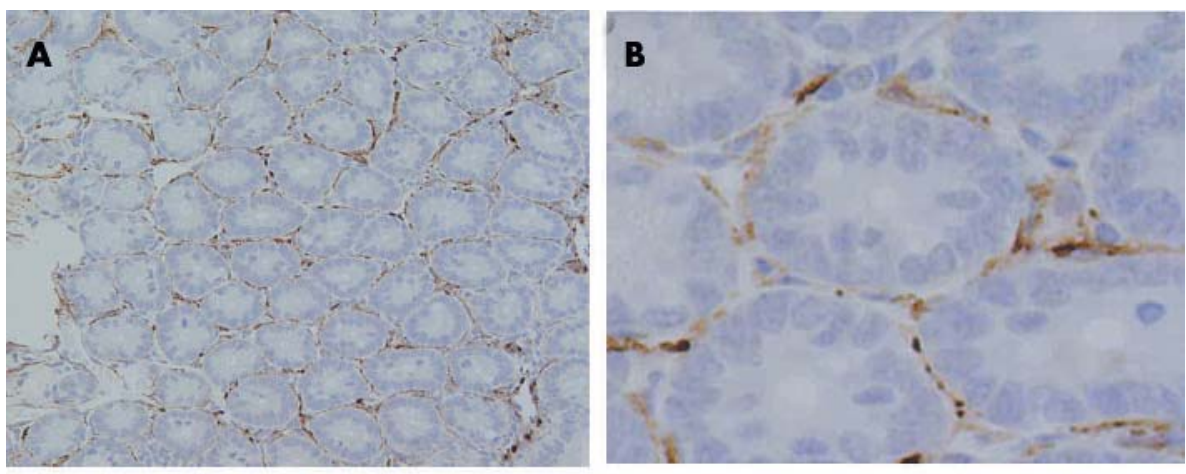

Figure 2 Normal mouse small (A, B) and large $(C, D)$ intestinal mucosa. Immunohistochemical stain for $\alpha$-smooth muscle actin. The pericryptal fibroblast sheath formed by pericryptal fibroblasts is closely embracing epithelial cells of normal intestinal crypts. Magnification $\times 100(\mathrm{~A}, \mathrm{C})$; $\times 400(B, D)$.
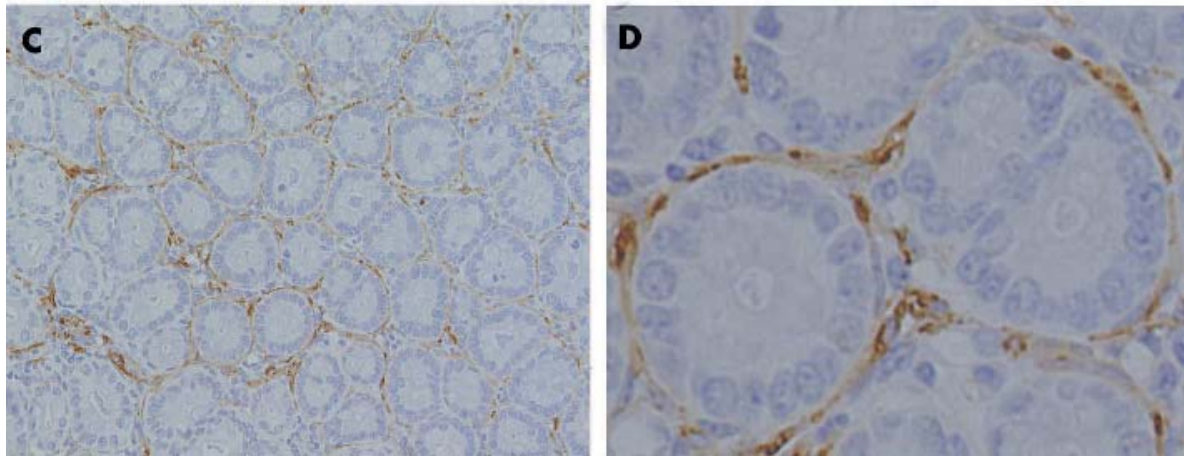

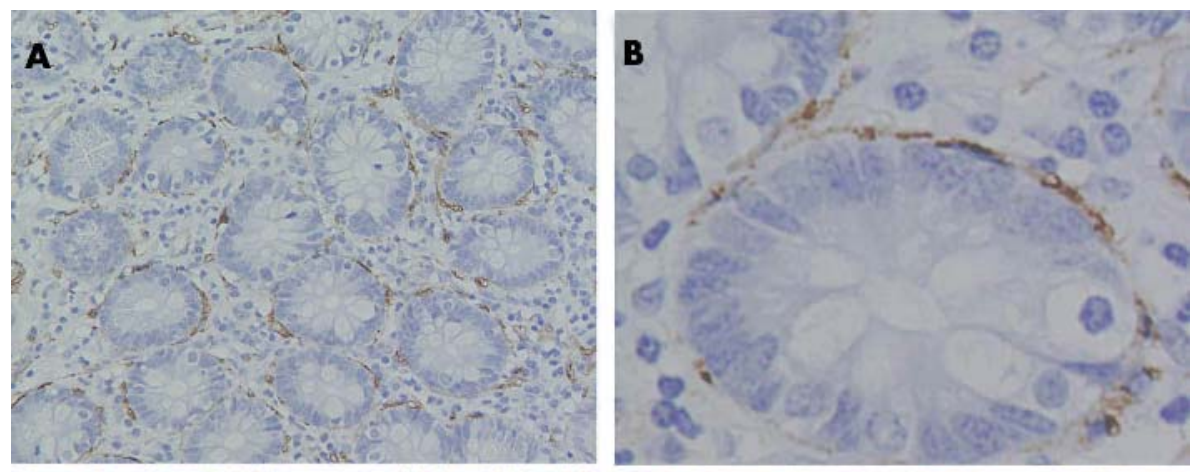

Figure 3 Normal human small (A, B) and large $(C, D)$ intestinal mucosa. Immunohistochemical stain for $\alpha$-smooth muscle actin. Pericryptal fibroblast sheath formed by pericryptal fibroblasts is closely embracing the epithelial cells of normal intestinal crypts. Magnification $\times 100(A, C)$; $\times 400(B, D)$
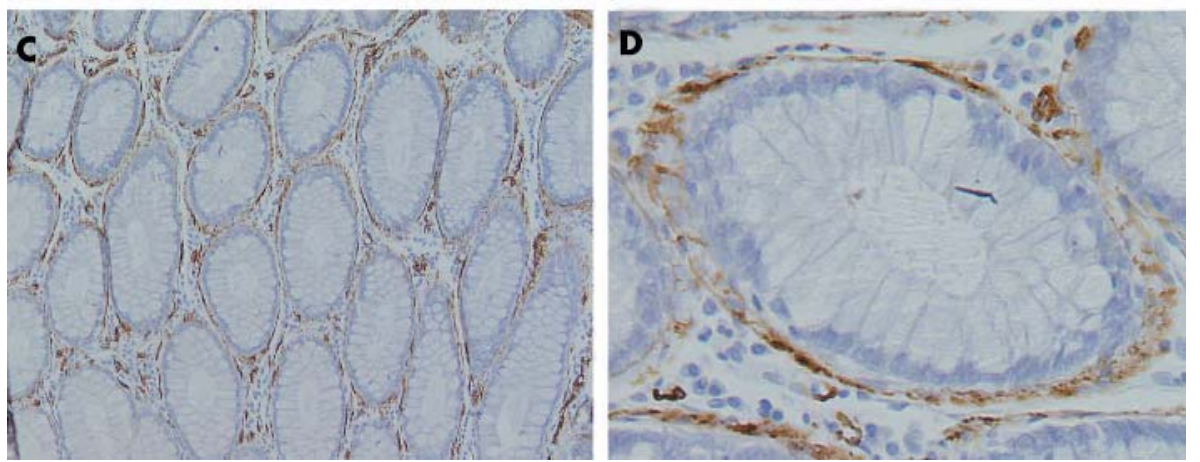

development with 3,3'-diaminobenzidine tetrahydrochloride (Wako Pure Chemical Industries, Osaka, Japan), slides were counterstained with haematoxylin and viewed under a light microscope.

\section{Fixation and preparation of tissue for electron microscopy}

Intestinal metaplastic mucosa from $\mathrm{Cdx} 2$ transgenic mouse stomach was fixed at $4{ }^{\circ} \mathrm{C}$ in $2 \%$ glutaraldehyde in PBS, followed by six washes in PBS with post fixation in $1 \%$ osmium tetroxide. Sections were examined under a Hitachi H-7500 scanning electron microscope.

\section{RESULTS}

To examine whether intestinal metaplasia is merely epithelial cell metaplasia or influences the underlying mesenchyme, we focused our attention on the PCFS in the mesenchyme. Light microscopic examination of normal mouse small and large intestine revealed fibroblasts subtending the epithelial basement membrane in the crypt (fig 1B, lC). In contrast, fibroblasts were not seen forming a sheath round the glands of normal mouse gastric mucosa (fig lA). These fibroblasts subjacent to the epithelium were easily distinguished from the rest of the mesenchymal elements of the lamina propria, which consist of a loose meshwork of collagen, fibroblasts, haematogenous cells, and capillaries.

$\alpha$-SMA is present in pericryptal fibroblasts and is used as a marker for pericryptal fibroblast cells. Pericryptal fibroblasts labelled by $\alpha$-SMA formed single cell layers that embraced the whole length of the crypts in the normal small and large intestinal mucosa of the mouse (fig 2) and humans (fig 3). $\alpha$-SMA positive PCFS was seen around many glands. Areas of abutment were broad and the sheath appeared continuous.

We previously generated $\mathrm{Cdx} 2$ transgenic mice expressing intestine specific transcription factor $C d x 2$ gene exclusively in the gastric epithelium under the control of the $\beta$-subunit gene promoter of rat $\mathrm{H}^{+} / \mathrm{K}^{+}$-ATPase. ${ }^{7} \mathrm{Cdx} 2$ transgenic mice developed normally into superficially healthy adults and showed intestinal metaplasia in the stomach up to 12 weeks of age. The gastric mucosa of $\mathrm{Cdx} 2$ transgenic mouse was completely replaced by intestinal metaplastic mucosa. Cdx2 induced intestinal metaplastic mucosa consisted of terminally differentiated intestinal epithelial cells, including absorptive enterocytes, goblet cells, and enteroendocrine cells. ${ }^{7}$ To clarify whether $\mathrm{Cdx} 2$ expression in gastric epithelium affects the underlying mesenchyme in vivo, the intestinal metaplastic mucosa of $\mathrm{Cdx} 2$ transgenic mouse stomach was stained for $\alpha$-SMA. The PCFS expressing $\alpha$-SMA was not seen around the glands of the normal gastric mucosa (fig 4A, B) whereas PCFS was easily recognised around the crypts of intestinal metaplastic mucosa of $\mathrm{Cdx} 2$ transgenic mouse stomach (fig 4C, 4D). In addition to mouse intestinal metaplastic mucosa, PCFS was also recognised around the glands of human intestinal metaplastic mucosa (fig 5C, D) while it was not seen around normal human gastric glands (fig 5A, B).

Electron microscopy revealed an even closer association between pericryptal fibroblasts and the epithelium than was revealed by light microscopy. In intestinal metaplastic mucosa of Cdx2 transgenic mouse stomach, the PCFS was in intimate contact with the epithelial basal lamina (fig 6). Fibroblasts were seen surrounding the base of the crypts in the intestinal metaplastic mucosa. These cells had large areas of contact with the epithelial basal lamina and had a plum fusiform shape (fig 6B, C).

As it is reported that the PCFS is significantly reduced in colorectal epithelial neoplasms, we examined the relationship between PCFS and gastric adenocarcinoma. We observed Cdx2 transgenic mice periodically without carcinogens or $H$ pylori infection. Cdx2 transgenic mice at 50 weeks of age indicated preservation of intestinal metaplasia and no gastric polyp formation, similar to those at 12 weeks (unpublished data). Cdx2 transgenic mice developed gastric polyps in the intestinal metaplastic lesion at two years after birth. Gastric polyps developed from intestinal metaplastic mucosa in all stomachs of $10 \mathrm{Cdx} 2$ transgenic mice examined. The polyps consisted of adenocarcinoma that invaded the submucosa or beyond (unpublished data). Using the adenocarcinoma, we examined the relationship between PCFS and adenocarcinoma. PCFS detected by immunohistochemical stain for $\alpha$-SMA was virtually absent in the area of gastric 

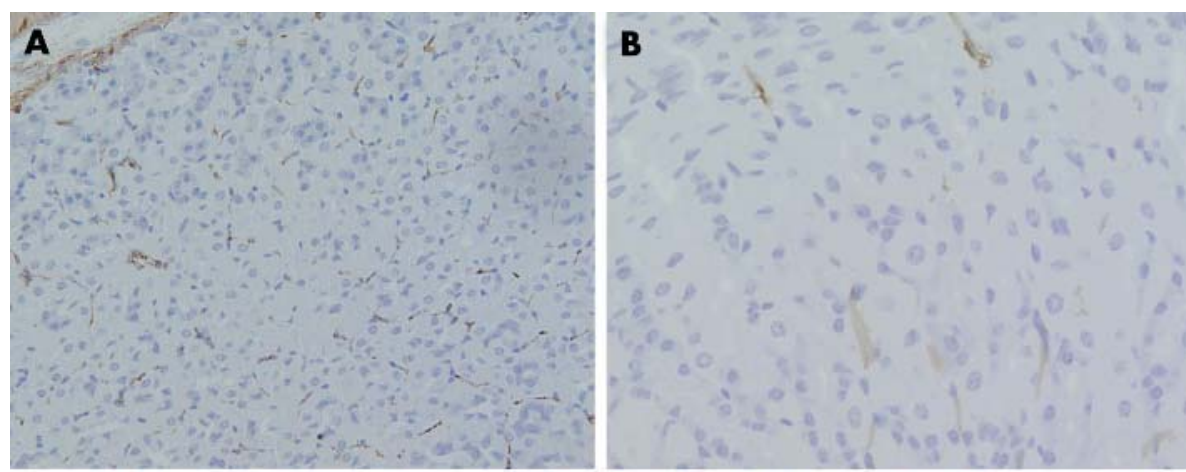

Figure 4 Normal and intestinal metaplastic mucosa of the mouse stomach. Immunohistochemical stain for $\alpha$-smooth muscle actin. Pericryptal fibroblast sheath (PCFS) formed by pericryptal fibroblasts is closely embracing the epithelial cells of the intestinal metaplastic mucosa (C, D) while PCFS is not seen in the normal gastric mucosa (A, B). Magnification $\times 100(A, C) ; \times 400(B, D)$.
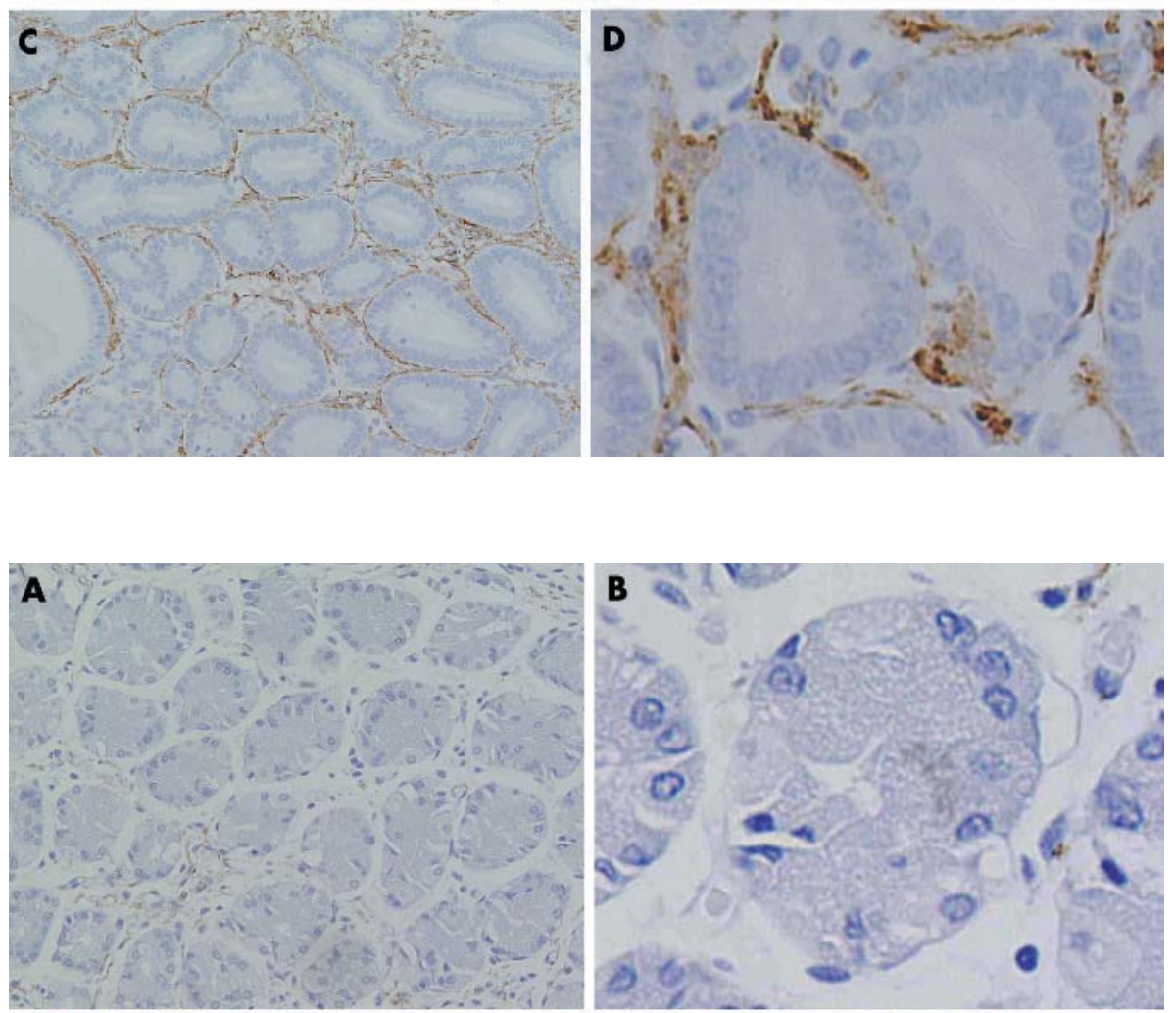

Figure 5 Normal and intestinal metaplastic mucosa of the human stomach. Immunohistochemical stain for $\alpha$-smooth muscle actin. Pericryptal fibroblast sheath (PCFS) formed by pericryptal fibroblasts is closely embracing the epithelial cells of the intestinal metaplastic mucosa (C, D) while PCFS is not seen in the normal gastric mucosa (A, B). Magnification $\times 100(A, C) ; \times 400(B, D)$.
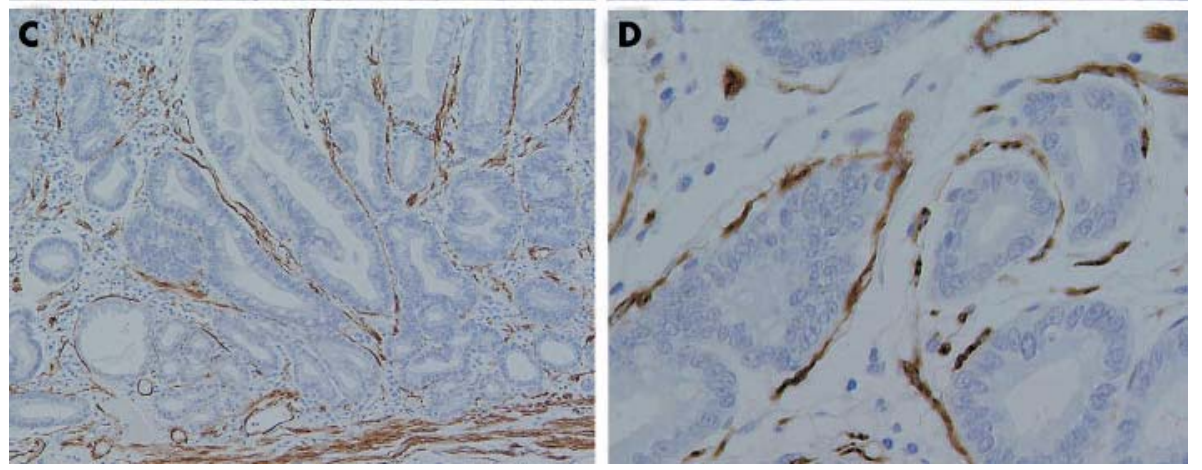

adenocarcinoma of both humans and mice (fig 7C, G) while PCFS was easily recognised in the intestinal metaplastic areas (fig 7A, E). PCFS was absent in all $10 \mathrm{Cdx} 2$ transgenic mouse and 10 human intestinal-type adenocarcinomas. Both human and murine gastric carcinomas were classified as intestinaltype according to the criteria of Lauren ${ }^{14}$ and as category 5.2 according to the five categories of the Vienna classification. ${ }^{15} 16$ We examined expression of $\mathrm{Cdx} 2$ in intestinal metaplasia and adenocarcinoma. Cdx2 staining for the adenocarcinoma lesion (fig 7D, H) was extremely weak compared with the intestinal metaplastic lesion (fig 7, B and F). The decrease in $\mathrm{Cdx} 2$ may explain, in part, the cause of the disappearance of PCFS in the gastric adenocarcinoma. There was no difference in immunoreactivities for Cdx2 and $\alpha$-SMA in intestinal metaplastic mucosa between 12 and 50 week old Cdx2 transgenic mice (data not shown).

\section{DISCUSSION}

Our results demonstrate that intestinal metaplasia is not merely epithelial metaplasia but also affects the underlying 

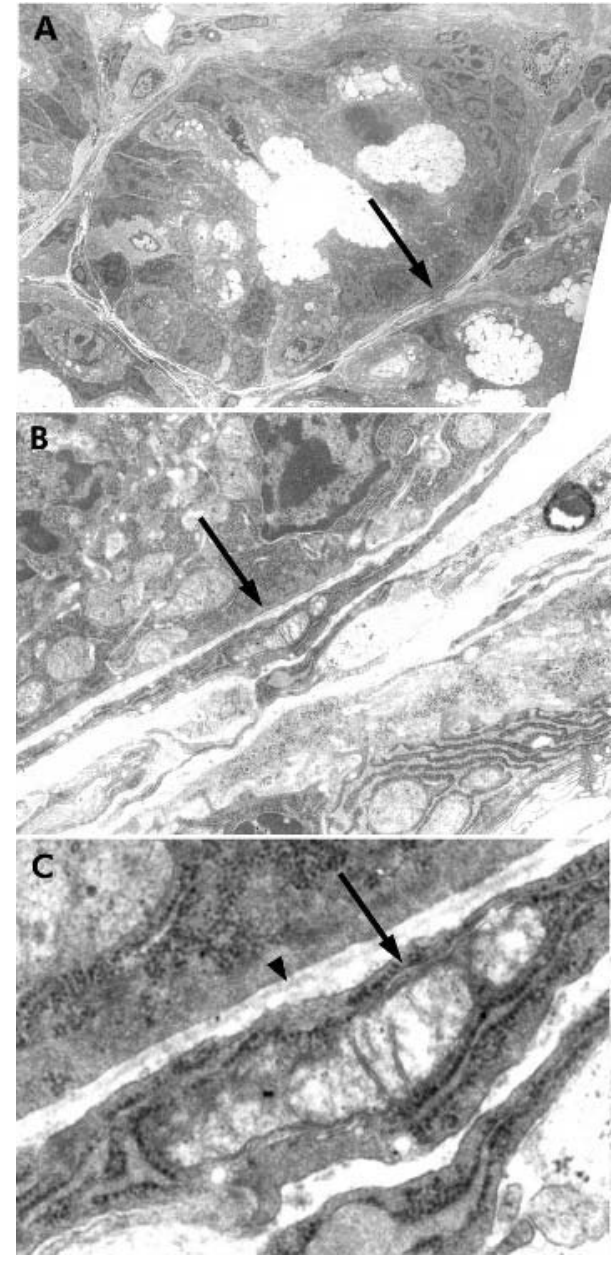

Figure 6 Electron micrograph of intestinal metaplastic mucosa in the Cdx2 transgenic mouse. The fibroblast (arrows) around the epithelial cells of the crypt demonstrates the fusiform shape and broad contact with the epithelial basal lamina (arrowhead) which is typical of the pericryptal fibroblast. The basement membrane is indicated by the arrowhead (C).

mesenchyme. The glands of intestinal metaplastic mucosa induced by a single homeobox gene, $\mathrm{Cdx} 2$, in transgenic mouse stomach were surrounded by PCFS via the basement membrane while normal gastric glands were not. PCFS was also seen around the glands of human intestinal metaplastic mucosa. Cdx2 has been reported to induce expression of various types of intestine specific genes that have consensus sequences for $\mathrm{Cdx} 2$ directly to bind. That $\mathrm{Cdx} 2$ has a pivotal role not only in differentiating intestinal metaplastic mucosal epithelial cells but also in inducing PCFS in the mesenchyme was demonstrated with $\mathrm{Cdx} 2$ transgenic mice previously generated by us. To the best of our knowledge, the present study is the first to show that in the intestinal metaplastic mucosa, the epithelium as well as the mesenchyme changes from a gastric-type mucosa to an intestinal-type mucosa through expression of transcription factor $\mathrm{Cdx} 2$ in the epithelium. Furthermore, as human intestinal metaplasia is mainly caused by H pylori infection, generation of the PCFS in human intestinal metaplastic mucosa indicates that the epithelium as well as the subjacent mesenchyme is transdifferentiated from the gastric type to the intestinal type by $H$ pylori infection.

The stomach and intestine are derived from the primitive undifferentiated gut tube formed during gastrulation but Cdx2 expression is only activated distal to the gastricduodenal junction. ${ }^{17}{ }^{18} \mathrm{Cdx} 2$ haploinsufficiency results in abnormal differentiation of midgut endoderm. ${ }^{19}$ The initial effect of heterozygous $\mathrm{Cdx} 2$ knockout mice, apparent in neonates, is seen as patches of forestomach epithelium present in the terminal ileum, caecum, or proximal colon. ${ }^{20}$ Thus in Cdx2 deficiency, cells which would normally differentiate into caecum and proximal colon follow a default pathway and form the stratified squamous epithelium characteristic of forestomach. In contrast, intestinal metaplastic epithelium was induced from gastric mucosa by expression of $\mathrm{Cdx} 2,{ }^{7}$ indicating that $\mathrm{Cdx} 2$ may be a key regulator for intestinal epithelial cell fate determination and differentiation. The intestinal metaplastic mucosa of $\mathrm{Cdx} 2$ transgenic mouse stomach also generated PCFS in the mesenchyme indirectly through expression of $\mathrm{Cdx} 2$ in the epithelium. The crypts of intestinal metaplastic mucosa in the human stomach were also embraced by pericryptal fibroblasts via the basement membrane. These results suggest that $\mathrm{Cdx} 2$ may have a master function in the coordinate process leading to both epithelial and mesenchymal differentiation during continuous renewal of the intestinal mucosa.

The embryonic gut of vertebrates consists of endodermal epithelium and surrounding mesenchyme. The involvement of epithelial-mesenchymal cell interactions in the control of cell differentiation during intestinal ontogeny and during continuous cell renewal in the mature organ has been demonstrated. ${ }^{21} 22$ Regional differentiation and morphogenesis of the gut epithelium requires tissue interactions involving instructive effects of mesenchyme and competence of the epithelium receiving them. ${ }^{23}$ The importance of the mesenchyme has been shown by in vivo models in which hybrid recombinants composed of fetal or adult mesenchyme associated with epithelial cells are grafted. ${ }^{24} 25$ The chick embryonic stomach and the fetal rat colon endoderms are induced to achieve a small intestinal morphological and functional cytodifferentiation (induction of sucrase-isomaltase gene expression) under the influence of the small intestinal mesenchyme. ${ }^{25}{ }^{26}$ In the avian embryonic muscular stomach epithelium (proventriculus), expression of embryonic chick pepsinogen gene, which is specific to developing glandular stomach epithelium, is regulated by the instructive influences of the chick glandular stomach mesenchyme. ${ }^{27}$ These effects of the mesenchyme on the epithelium indicate that mesenchyme is important in morphogenetic processes and in maintenance of the tissuelar integrity in the gut.

Laminin-1, an extracellular matrix component of the basement membrane, is known to stimulate intestinal cell differentiation. ${ }^{28-31}$ The differentiating effect of laminin-1 coatings on Caco2-TC7 cells is accompanied by upregulation of $\mathrm{Cdx} 2,{ }^{31}$ suggesting that $\mathrm{Cdx} 2$ plays a key role in the cascade of events involved in extracellular matrix mediated intestinal cell differentiation. These data indicate that intestinal mesenchyme influences intestinal epithelial differentiation. Conversely, the present results showed that $\mathrm{Cdx} 2$ induced intestinal epithelium affected PCFS formation in the mesenchyme. PCFS in intestinal metaplasia of the stomach was formed simply by expressing $\mathrm{Cdx} 2$ in gastric mucosal epithelial cells. The results indicate that expression of $\mathrm{Cdx} 2$ in epithelial cells directly plays a pivotal role in generating PCFS around $\mathrm{Cdx} 2$ expressing glands. It is therefore possible that the intestinal metaplastic mucosa of $\mathrm{Cdx} 2$ transgenic mouse stomach results from direct interaction of $\mathrm{Cdx} 2$ protein with the promoters of enterocytic differentiation markers as well as from indirect effects of the mesenchyme. Taken together, these observations indicate that reciprocal interactions between epithelium and mesenchyme might be important for the development and differentiation of intestinal mucosa, including both epithelium and mesenchyme.

PCFS has been investigated in colorectal carcinoma by immunohistochemistry employing an antibody against 

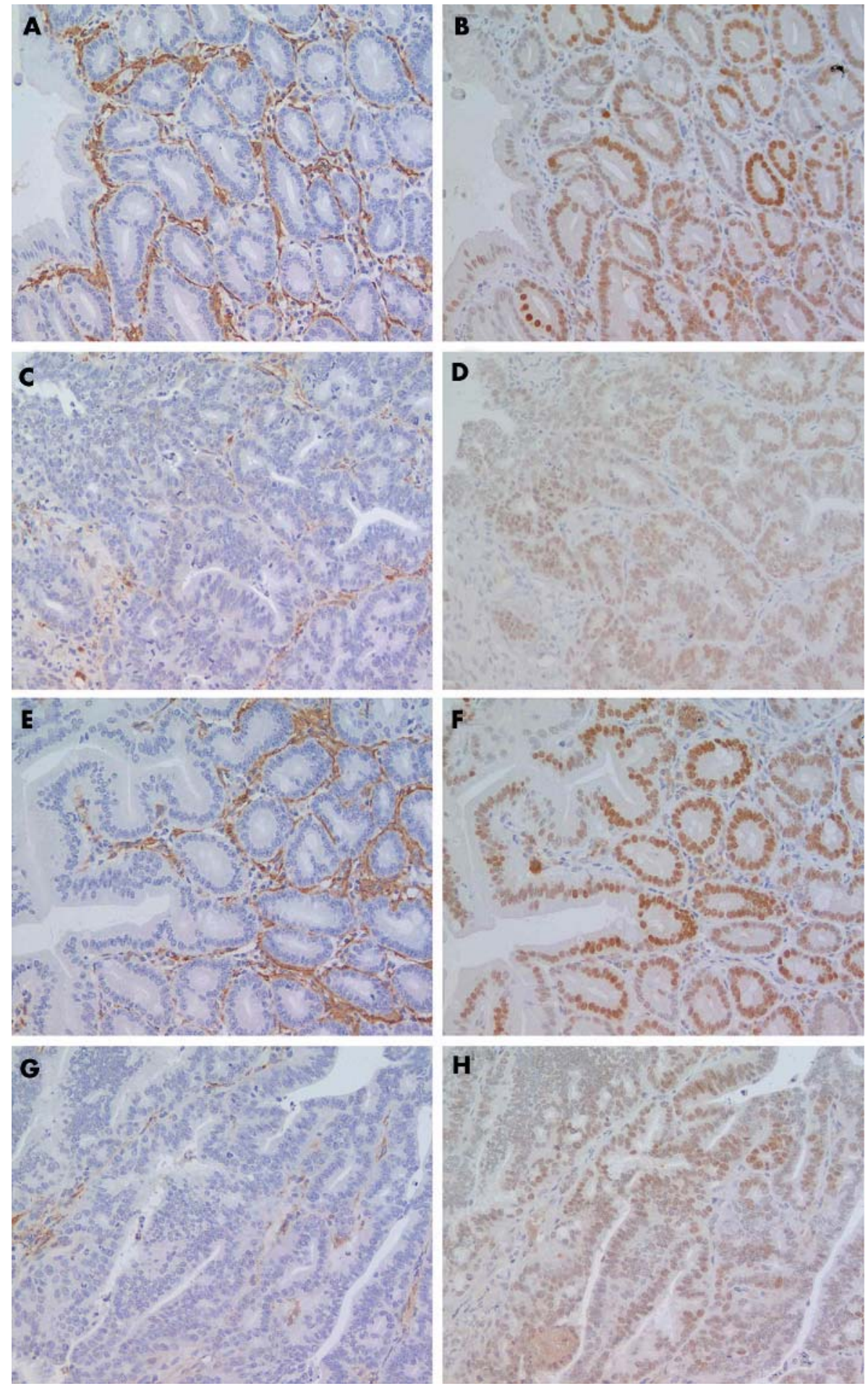

Figure 7 Relationship between $\mathrm{Cd} \times 2$ and $\alpha$-smooth muscle actin $(\alpha$-SMA) positive pericryptal fibroblast sheath (PCFS) in vivo. Gastric intestinal metaplasia of $C d \times 2$ transgenic mice (A, B) and humans ( $E, F)$. Gastric adenocarcinoma of $C d \times 2$ transgenic mice $(C, D)$ and humans $(G, H)$. Immunohistochemical staining for $\alpha-\operatorname{SMA}(A, C, E, G)$ and $C d \times 2(B, D, F, H)$. Cdx2 expressing intestinal metaplastic epithelial cells are surrounded by $\alpha$-SMA positive pericryptal fibroblasts in the intestinal metaplastic mucosa (A, B, E, F) while PCFS is not recognised in the adenocarcinoma (C, G). $\alpha-S M A$ positive cells in gastric carcinoma tissue is not histologically PCSF. Cdx2 staining for the adenocarcinoma lesion $(D, H)$ is extremely weak compared with the intestinal metaplastic lesion (B, F). Magnification $\times 200$.

$\alpha$-SMA. ${ }^{32}$ The amount of PCFS was reduced significantly in colorectal carcinoma. A significant reverse correlation was seen between the degree of colorectal neoplasia progression and the quantity of neoplastic glands with PCFS. ${ }^{33}$ Nakayama et al reported the relationship between $\alpha$-SMA positive stromal cells and gastric carcinoma. ${ }^{34}$ Their $\alpha$-SMA positive stromal cells were high molecular weight caldesmon negative and different from PCFS which is positive for high molecular weight caldesmon. ${ }^{34}$ The relationship between PCFS and gastric carcinoma has not been investigated to date. In the present study, we have shown that PCFS also disappeared in the gastric carcinoma of both humans and mice, similar to 
the colonic carcinoma. Although intestinal-type gastric carcinoma is thought to develop from gastric epithelium that has undergone intestinal metaplasia, intestinal-type gastric carcinoma cells were not surrounded by PCFS, which is different from the intestinal metaplastic mucosa around the gastric carcinoma. The presence of mesenchymal cells or mesenchyme derived extracellular matrix molecules has been shown to play a fundamental role in epithelial cell proliferation and differentiation via epithelial-mesenchymal cell interactions. ${ }^{12} 1335$ Mesenchymal cells express important growth factors whose receptors are found on the epithelial cell surface which is exemplified by expression of hepatocyte growth factor/scatter factor and of keratinocyte growth factor which regulate epithelial cell behaviour. ${ }^{36}$ These instructive actions of the mesenchyme on gastrointestinal tract epithelial cells indicate that the generation and disappearance of PCFS might be closely related to the development of intestinal-type gastric carcinoma.

In conclusion, ectopic expression of $\mathrm{Cdx} 2$ in gastric mucosal epithelial cells induced not only intestinal epithelial cell differentiation but also PCFS generation in the mesenchyme, indicating that $\mathrm{Cdx} 2$ may be important for intestinal mucosal differentiation involving both the epithelium and mesenchyme. In addition, PCFS in the mesenchyme may be related to the development of gastric carcinoma.

\section{ACKNOWLEDGEMENTS}

This work was supported in part by Grants-in-Aid for Scientific Research (B) ( 12470126 for HM, 13470122 for KS), Grants-in-Aid for Scientific Research (C) (14570501 for HM), and Grants-in-Aid for Exploratory Research (14657134 for KS) from Japan Society for the Promotion of Science. We are grateful for the expert technical assistance provided by H Nagaki and K Sasaki.

\section{Authors' affiliations}

H Mutoh, K Satoh, H Osawa, T Tomiyama, H Kita, T Yoshida, K Tamada, H Yamamoto, N Isoda, K Ido, K Sugano, Department of Gastroenterology, Jichi Medical School, Tochigi, Japan

S Sakurai, Department of Pathology, Jichi Medical School, Tochigi, Japan

Conflict of interest: None declared.

\section{REFERENCES}

1 Correa P. Human gastric carcinogenesis: a multistep and multifactorial process - First American Cancer Society Award Lecture on Cancer Epidemiology and Prevention. Cancer Res 1992;52:6735-40.

2 Eda A Osawa H, Yanaka I, et al. Expression of homeobox gene CDX2 precedes that of $C D X 1$ during the progression of intestinal metaplasia. J Gastroenterol 2002;37:94-100.

3 Satoh K, Mutoh H, Eda A, et al. Aberrant expression of CDX2 in the gastric mucosa with and without intestinal metaplasia: effect of eradication of Helicobacter pylori. Helicobacter 2002;7:192-8.

4 Almeida R, Silva E, Santos-Silva F, et al. Expression of intestine-specific transcription factors, $C D X 1$ and $C D X 2$, in intestinal metaplasia and gastric carcinomas. J Pathol 2003;199:36-40.

5 Bai YQ, Yamamoto H, Akiyama Y, et al. Ectopic expression of homeodomain protein CDX2 in intestinal metaplasia and carcinomas of the stomach. Cancer Lett 2002; 176:47-55.

6 Mizoshita T, Inada K, Tsukamoto T, et al. Expression of $\mathrm{Cdx} 1$ and $\mathrm{Cdx} 2$ mRNAs and relevance of this expression to differentiation in human gastrointestinal mucosa-with special emphasis on participation in intestinal metaplasia of the human stomach. Gastric Cancer 2001:4:185-91.

7 Mutoh H, Hakamata Y, Sato K, et al. Conversion of gastric mucosa to intestinal metaplasia in $\mathrm{Cd} \times 2$-expressing transgenic mice. Biochem Biophys Res Commun 2002;294:470-9.

8 Pascal RR, Kaye Gl, Lane N. Colonic pericryptal fibroblast sheath: replication, migration, and cytodifferentiation of a mesenchymal cell system in adult tissue.
I. Autoradiographic studies of normal rabbit colon. Gastroenterology 1968;54:835-51.

9 Kaye GI, Lane N, Pascal RR. Colonic pericryptal fibroblast sheath: replication, migration, and cytodifferentiation of a mesenchymal cell system in adult tissue. II. Fine structural aspects of normal rabbit and human colon. Gastroenterology 1968;54:852-65

10 Desaki J, Fujiwara T, Komuro T. A cellular reticulum of fibroblast-like cells in the rat intestine: scanning and transmission electron microscopy. Arch Histol Jpn 1984:47:179-86.

11 Naftalin RJ, Pedley KC. Regional crypt function in rat large intestine in relation to fluid absorption and growth of the pericryptal sheath. J Physiol 1999; 514:211-27.

12 Birchmeier C, Birchmeier W. Molecular aspects of mesenchymal-epithelial interactions. Annu Rev Cell Biol 1993;9:511-40.

13 Kedinger M, Freund JN, Launary JF, et al. Cell interactions through basement membrane in intestinal development and differentiation. In: Sanderson IR, Walker WA, eds. Development of the gastrointestinal tract. London: BC Decker Inc, 1999:83-102.

14 Lauren P. The two histological main types of gastric carcinoma: diffuse and socalled intestinal-type carcinoma. Acta Pathol Microbiol Scand 1965:64:31-49.

15 Schlemper RJ, Riddell RH, Kato Y, et al. The Vienna classification of gastrointestinal epithelial neoplasia. Gut 2000;47:251-5.

16 Dixon MF. Gastrointestinal epithelial neoplasia: Vienna revisited. Gut 2002;51:130-1.

17 Silberg DG, Swain GB, Suh ER, et al. Cdx1 and Cdx2 expression during intestinal development. Gastroenterology 2000;119:961-71.

18 James R, Erler T, Kazenwadel J. Structure of the murine homeobox gene cdx2. Expression in embryonic and adult intestinal epithelium. J Biol Chem 1994;269:15229-37.

19 Chawengsaksophak K, James R, Hammond VE, et al. Homeosis and intestinal tumours in Cdx2 mutant mice. Nature 1997;386:84-7.

20 Beck F, Chawengsaksophak K, Waring $P$, et al. Reprogramming of intestinal differentiation and intercalary regeneration in $\mathrm{Cd} \times 2$ mutant mice. Proc Natl Acad Sci U S A 1999;96:7318-23.

21 Simon-Assmann P, Kedinger M. Heterotypic cellular cooperation in gut morphogenesis and differentiation. Semin Cell Biol 1993:4:221-30.

22 Simon-Assmann P, Kedinger M, De Arcangelis A, et al. Extracellular matrix components in intestinal development. Experientia 1995;51:883-900.

23 Yasugi S. Regulation of pepsinogen gene expression in epithelial cells of vertebrate stomach during development. Int J Dev Biol 1994;38:273-9.

24 Kedinger M, Simon PM, Grenier JF, et al. Role of epithelial-mesenchymal interactions in the ontogenesis of intestinal brush-border enzymes. Dev Biol 1981;86:339-47.

25 Duluc I, Freund JN, Leberquier $C$, et al. Fetal endoderm primarily holds the temporal and positional information required for mammalian intestinal development. J Cell Biol 1994;126:211-21.

26 Haffen KKM, Simon-Assmann P. Cell-contact-dependent regulation of enterocytic differentiation. New York: Raven Press, 1989.

27 Fukuda K, Ishii Y, Saiga H, et al. Mesenchymal regulation of epithelial gene expression in developing avian stomach: $5^{\prime}$-flanking region of pepsinogen gene can mediate mesenchymal influence on its expression. Development 1994:120:3487-95

28 Hahn U, Stallmach A, Hahn EG, et al. Basement membrane components are potent promoters of rat intestinal epithelial cell differentiation in vitro. Gastroenterology 1990;98:322-35

29 Vachon PH, Beaulieu JF. Extracellular heterotrimeric laminin promotes differentiation in human enterocytes. Am J Physiol 1995;268:G857-67.

30 Basson MD, Turowski G, Emenaker NJ. Regulation of human (Caco-2) intestinal epithelial cell differentiation by extracellular matrix proteins. Exp Cell Res 1996;225:301-5.

31 Lorentz O, Duluc I, Arcangelis AD, et al. Key role of the $C d \times 2$ homeobox gene in extracellular matrix-mediated intestinal cell differentiation. J Cell Biol 1997; 139:1553-65.

32 Yao T, Tsuneyoshi M. Significance of pericryptal fibroblasts in colorectal epithelial tumors: a special reference to the histologic features and growth patterns. Hum Pathol 1993;24:525-33.

33 Li A, Hasui K, Yonezawa S, et al. Immunohistochemical analysis of pericryptal fibroblast sheath and proliferating epithelial cells in human colorectal adenomas and carcinomas with adenoma components. Pathol Int 1999;49:426-34

34 Nakayama H, Enzan H, Miyazaki E, et al. Alpha smooth muscle actin positive stromal cells in gastric carcinoma. J Clin Pathol 2002;55:741-4.

35 Simo P, Simon-Assmann P, Arnold C, et al. Mesenchyme-mediated effect of dexamethasone on laminin in cocultures of embryonic gut epithelial cells and mesenchyme-derived cells. J Cell Sci 1992;101:161-71.

36 Birchmeier C, Meyer D, Riethmacher D. Factors controlling growth, motility, and morphogenesis of normal and malignant epithelial cells. Int Rev Cytol $1995 ; 160: 221-66$. 